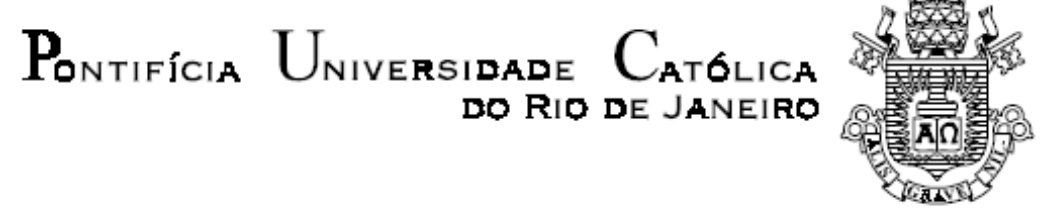

Nathalia Corrêa Calmon

O Milagre do Corpo a partir de Jerusalém de Gonçalo M. Tavares

Dissertação de Mestrado

Dissertação apresentada ao Programa de Pós-Graduação em Letras da PUC - Rio como requisito parcial para a obtenção do título de Mestre em Letras.

Orientadora: Ana Paula Veiga Kiffer 
Pontifícia Universidade Catglica $_{\text {a }}$

DO RIO DE JANEIRO

Nathalia Corrêa Calmon

\section{O Milagre do Corpo a partir de Jerusalém \\ de Gonçalo M. Tavares}

Dissertação apresentada como requisito parcial para obtenção do grau de Mestre pelo Programa de Pós-Graduação em Letras do Departamento de Letras do Centro de Teologia e Ciências Humanas da PUC-Rio. Aprovada pela Comissão Examinadora abaixo assinada.

Prof $^{a}$. Ana Paula Veiga Kiffer
Orientadora
Departamento de Letras - PUC-Rio

Prof ${ }^{\mathrm{a}}$. Marília Rothier Cardoso Departamento de Letras - PUC-Rio

Prof ${ }^{\mathrm{a}}$. Madalena Simões de Almeida Vaz Pinto

UFRJ

Prof. Paulo Fernando Carneiro de Andrade Coordenador Setorial do Centro de Teologia e Ciências Humanas - PUC-Rio 
Todos os direitos reservados. É proibida a reprodução total ou parcial do trabalho sem autorização da universidade, do autor e do orientador.

\section{Nathalia Corrêa Calmon}

Graduou-se em Letras - Bacharelado em Língua Portuguesa e Literaturas Correspondentes, na PUC-Rio, em 2006.

Ficha Catalográfica

Calmon, Nathalia Corrêa

O milagre do corpo a partir de Jerusalém de Gonçalo M. Tavares / Nathalia Corrêa Calmon ; orientadora: Ana Paula Veiga Kiffer. -2009 .

89 f. ; $30 \mathrm{~cm}$

Dissertação (Mestrado em Letras)Pontifícia Universidade Católica do Rio de Janeiro, Rio de Janeiro, 2009.

Inclui bibliografia

1. Letras - Teses. 2. Milagre. 3. Corpo. 4. Jerusalém. 5. Tavares, Gonçalo M. I. Kiffer, Ana Paula Veiga. II. Pontifícia Universidade Católica do Rio de Janeiro. Departamento de Letras. III. Título. 


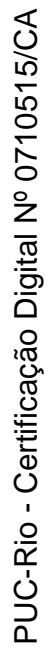

A minha mãe:

Porque nós vencemos. 


\section{Agradecimentos}

A minha mãe, que me fez comida, velou o sono e mazelas, e me botou pra ver o Dr. House nas horas de tensão.

A minha avó, porque mesmo não entendendo pra que serve um mestrado vive contando pra todo mundo que eu faço. E também, e talvez principalmente, por ter me introduzido ao mundo das histórias, o que me levou à paixão pela literatura.

A meu pai, porque sem falar no assunto mais de uma vez, me convenceu a prosseguir até aqui.

A Domingos Guimaraens, porque sem ele nada disso.

A Aline Jobim e Felipe Kaizer, porque apareceram. Amigos. Meus super-heróis. Divertidos. Designers.

A Débora Landsberg, e João Polessa, porque são os únicos que me fazem ficar horas no telefone, desde a graduação.

A Daniel Paiva, pelas revoluções.

A Bruno Ferreira Augusto, por ser irmão. Porque me mostrou que eu podia escrever para além do meu quarto. Porque de interlocutor em textos adolescentes virou interlocutor intelectual.

A Any Dana, porque de atriz virou acadêmica. Sempre amiga. Consultora de cultura judaica.

A Tainá Gaidano por ser irmã.

A Jonas Sá por existir e ainda cantar.

A Elena Gaidano por ser a melhor madrinha, de todas as horas, que agora além de tudo, ainda dá aula de literatura.

À Sonia Frazão e Daniel Corrêa: importantes. 
A Eva e Cléia, pelo apoio sem precedentes.

À Fanfarra Paradiso, a Lucio Branco e a Lucio K, pelas oportunidades.

E ainda:

A Pontifícia Universidade Católica,

A Chiquinha (sempre sorrisos), Lusinete e Carla. Todas tão capazes de acalmar os ânimos de uma mestranda exaltada.

A todos os professores que passaram por essa minha jornada da PUC, desde a graduação, mas em especial, Karl, Júlio e Heidrun que reencontrei nestes dois últimos anos de mestrado.

E, ainda mais especialmente, mesmo que fora da faculdade:

A Paulo Henriques Britto porque sem suas iluminações de sala de aula, eu não teria descoberto que queria estudar literatura contemporânea.

À Madalena Vaz Pinto, pelo carinho, pela atenção e por compartilhar o interesse por Gonçalo Tavares, esperando que dessa afinidade ainda possam surgir mais encontros, partilhas e boas conversas.

A Marília Rothier, por toda a contribuição afetiva e teórica, todo o interesse e generosidade, sem os quais boa parte das tentativas de construção de pensamento deste trabalho, não teriam acontecido. Esperando ter retribuído de alguma forma, e que o tempo ainda nos proporcione mais aproximações.

A Ana Paula Kiffer, por ser orientadora. Por ser toda a presença, que foi contribuição para a construção de pensamentos, incentivo ao trabalho, chamadas à realidade, paciência, rigor, discordâncias e infinita generosidade. Por acreditar. Por ouvir e falar sempre com essa convicção que está para além de apenas dizer coisas, mas ser essa presença afetiva, e ainda séria. Por toda essa sinceridade e honestidade que é o que involuntariamente busco em quem acaba sendo mesmo exemplo, de que é possível. 


\section{Resumo}

Calmon, Nathalia Corrêa; Kiffer, Ana Paula Veiga. O milagre do corpo a partir de Jerusalém - de Gonçalo M. Tavares. Rio de Janeiro, 2009. 89p. Dissertação de Mestrado - Departamento de Letras, Pontifícia Universidade Católica do Rio de Janeiro.

Este trabalho oferece ao leitor uma composição em mosaico, de uma voz subjetiva, que se alia em uma primeira instância à voz de Gonçalo M. Tavares (sobretudo em seu romance Jerusalém), e posteriormente, às vozes de: Gilles Deleuze, Georges Bataille, José Gil, David Lapoujade, Antonin Artaud, Samuel Beckett e Clarice Lispector para juntos percorrermos a questão do corpo em sofrimento bem como seus possíveis milagres.

\section{Palavras-chave}

Milagre; Corpo; Jerusalém; Gonçalo M. Tavares; Gonçalo Tavares; Tavares, Gonçalo; Tavares, Gonçalo M. 


\section{Abstract}

Calmon, Nathalia Corrêa; Kiffer, Ana Paula Veiga (Advisor). The Miracle of the Body from Jerusalém by Gonçalo M. Tavares. Rio de Janeiro, 2009. 89p. MSc. Dissertation - Departamento de Letras, Pontifícia Universidade Católica do Rio de Janeiro.

This work offers its readers a mosaic arrangement of a subjective voice that connects, in the beginning, Gonçalo M. Tavares' voice (mainly in his novel Jerusalém), and afterwards the voices of Gilles Deleuze, Georges Bataille, José Gil, David Lapoujade, Antonin Artaud, Samuel Beckett, and Clarice Lispector so that together we can run through the question of the body, its sufferings and possible miracles.

\section{Keywords}

Miracle; Body; Jerusalem; Jerusalém; Tavares, Gonçalo; Tavares, Gonçalo M; Gonçalo M. Tavares; Gonçalo Tavares 


\section{Sumário}

1. Introdução 11

1.1. Primeira Introdução 11

$\begin{array}{ll}\text { 1.2. Segunda Introdução } & 13\end{array}$

2. Por que Jerusalém? 16

2.1 Os contemporâneos de Gonçalo Tavares 16

$\begin{array}{ll}2.2 \text { Por que Literatura Contemporânea? } & 17\end{array}$

2.3 A Literatura não deve se ausentar de mexer na vida 19

2.4 A Literatura, os Afetos, o Sujeito 23

2.5 Por que o corpo na literatura? 24

2.6 O corpo instrumento de fuga 27

2.7 Jerusalém-A História 27

2.8 Quais são os corpos de Jerusalém? 32

2.9 Os Loucos 32

2.10 Mylia e As Internas 33

2.11 Ernst e Kaas 34

2.12 O que ficará de fora $\quad 35$

3. O Corpo e Suas Fronteiras 37

$\begin{array}{ll}3.1 \mathrm{~A} \text { pele } & 37\end{array}$

3.2 Os Três Erotismos $\quad 39$

3.3 Erotismo, imaginação, transgressão 42

3.4 A ameaça do fascínio 43

3.5 Da Proibição à Transgressão, da Transgressão à Punição 44

3.6 Para começar a entender a resistência $\quad 47$

3.7 Da Profundidade, Do Hades, Do Corpo e

3.8 As quatro questões que se colocam $\quad 50$

4. Da Resistência 55

4.1A potência liberada do ato 55 
4.2 O Grito de Kaas $\quad 59$

$\begin{array}{ll}4.3 \text { A aparência monstruosa } & 60\end{array}$

4.4 A resistência erótica dos corpos ou uma erótica monstruosa 63

4.5 A Memória de Mylia $\quad 65$

4.6 O isolamento de Mylia $\quad 69$

$\begin{array}{ll}4.7 \text { O Milagre de Mylia } & 71\end{array}$

5. Conclusão 77

5.1 Espécie de conclusão $\quad 77$

5.2 Segunda espécie de conclusão 77

$\begin{array}{ll}5.3 \text { E é assim que eu sobrevivo } & 78\end{array}$

$5.4 \mathrm{O}$ milagre de Mylia, os nossos milagres (Mylagres?) 84

6. Referências bibliográficas 86 